\title{
The Silence of the Doctors
}

\section{Fifty Years After Nuremberg}

\begin{abstract}
When Seiss-Inquart, Reich Commissar for the Occupied Netherlands Territories, wanted to draw the Dutch physicians into the orbit of activities of the German medical profession, he did not tell them you must send your chronic patients to death factories' or 'you must give lethal injections at government request in your offices,' but he couched his order in most careful and superficially acceptable terms... It is the duty of the doctor, through advice and effort, conscientiously and to his best ability, to assist as helper the person entrusted to his care in the maintenance, improvement and re-establishment of his vitality, physical efficiency and health. The accomplishment of this duty is a public task.'
\end{abstract}

The physicians of Holland unanimously rejected this seemingly banal Nazi order, turned in their medical licenses, and remained adamant even after 100 doctors were sent to concentration camps. They insisted that the patient-doctor relationship is private, not public; they refused the Nazi utilitarian ideology that valued prevention and rehabilitation for productive labor over caring, and that justified "the mass extermination of the chronically sick in the interest of saving 'useless' expenses to the community as a whole." Having balked at this first, small step, not a single Dutch physician subsequently participated in euthanasia or nontherapeutic sterilization.

Today, corporate medicine cajoles us to collaborate in small betrayals of patients' trust; to gag ourselves in the examining room but reveal patients' secrets in the billing office; to accept payments for denying care; to avoid the sickest, who are unprofitable; to prescribe only pills for psychiatric illnesses; to allow accountability to a health plan to displace devotion to a patient.

As Liang points out in this issue of $J G I M,{ }^{2}$ explicit gag clauses are merely the baldest expression of the corporate power that increasingly distorts medicine. Though his exposition of the doctor's dilemma is eloquent, his solutions are insufficient. His proposals to end insurers' immunity from liability and to require public hearings for delisted ("deselected") physicians are unobjectionable. But such regulations would do little to protect patients or to change the constellation of power that allows corporations to dictate care.

Although we support the extension of tort liability to HMOs, we know from studies of physician malpractice that litigation correlates only weakly with negligence, ${ }^{3}$ and is a poor tool for quality improvement. Few lawsuits target failures in caring, the most endangered among the medical species. Moreover, because bad outcomes predict malpractice awards more surely than bad care does, the threat of litigation could even amplify incentives for HMOs to avoid the sick.

Delisting is a big gun in HMOs' physician-control armamentarium, but subtler means like risk sharing are far more common, and probably as effective. For instance, in some plans, bonuses for primary care doctors who minimize referrals, tests, and inpatient days may account for virtually all of the doctors' net income (after practice expenses). ${ }^{4}$ Such plans don't need to delist expensive practitioners in order to get rid of them; physicians who are not independently wealthy are forced to delist themselves.

As our Dutch colleagues recognized, the fundamental ethical question for doctors is, "for whom do we work?" Corporate executives' primary fiduciary responsibility is to shareholders; their metric for judging care is necessarily financial. Allowing them power over medical work abdicates the primacy of the patient. Even in not-for-profit settings, our market-driven system makes institutional survival contingent on emulating for-profit organizations, resulting in pressure to treat patients as commodities, increase throughput, avoid the unprofitable, and skimp on caring. Regulations that merely proscribe current transgressions invite new profit-driven abuses to seep through the inevitable loopholes.

The monstrous abuses by Nazi medical researchers are well known. German clinicians also killed more than 200,000 disabled Germans. Cost and benefit calculus was used to justify such "final medical therapy." A pamphlet called on physicians to "[make] clear to anyone suffering from an incurable disease that the useless dissipation of costly medications drawn from the public store cannot be justified." 5 The system diffused and distanced responsibility. The patient's physician merely filled out a form detailing the patient's condition. A committee of senior physicians reviewed these forms and decided whether continued treatment was worthwhile, following guidelines prepared by public health specialists and administrators. Finally, a committee of senior professors was required to approve "final medical therapy." Each physician's role was minor. "'I simply filled out a form.' 'I only gave an opinion.' 'I only helped draft the guidelines." 5

We do not suggest any equivalence between Nazi medicine and corporate medicine of the 1990s. But extreme transgressions often shed light on more subtle moral dilemmas. Modern concepts of the ethics of medical research were born at Nuremberg. The crimes of Nazi clinicians similarly illuminate ethical boundaries of day-today practice: the imperative that doctors work for their 
patient; the peril of defining ourselves as mere technicians of biology, of abandoning the Samaritan traditions and caring roots of our profession; the hazard of acquiescence in small moral compromises because we believe ourselves powerless to change "the system."

Profit-driven medicine is a failure. It is expensive, bureaucratic, denies care to many in need, and increasingly confronts physicians with ethically untenable demands. Abolition, not regulation, is the appropriate response to injustice. The system is made by people and can also be changed by people. Communities need our moral leadership; clear-eyed statements that medicine is gone awry, that turning patients into profit centers corrupts the soul of medicine; even civil disobedience to disrupt the businessas-usual politesse of corporate care. Let us again proclaim the primacy of the patient.-DAvid U. HIMmelsteIN,
MD, STEFFIE WoolhandleR, MD, MPH, Department of Medicine, Cambridge (Mass.) Hospital and Harvard Medical School.

\section{REFERENCES}

1. Alexander L. Medical science under dictatorship. N Engl J Med. 1949;241:39-47.

2. Liang BA. The practical utility of gag clause legislation. J Gen Intern Med. 1998;13:419-21.

3. Brennan TA, Sox CM, Burstin HR. Relation between negligent adverse events and the outcomes of medical-malpractice litigation. $\mathrm{N}$ Engl J Med. 1996;335:1963-7.

4. Woolhandler S, Himmelstein DU. Extreme risk: the new corporate proposition for physicians. N Engl J Med. 1995;333:1706-8. Editorial.

5. Gallagher H. Managed care: the German experiment. Physicians for a National Health Program Newsletter. July 1997:5-9.

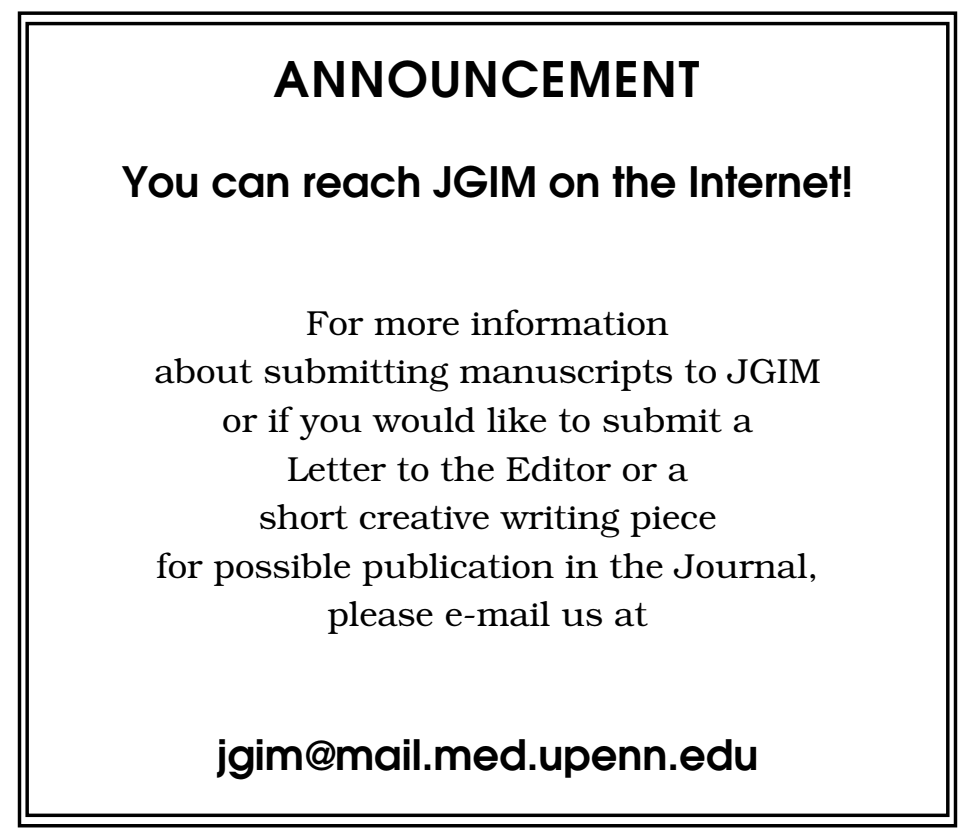

